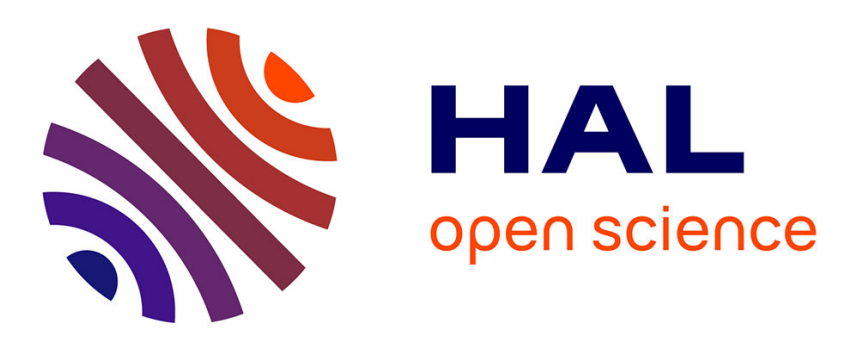

\title{
Histamine (re)uptake by astrocytes: an experimental and computational study
}

Katja Perdan-Pirkmajer, Janez Mavri, Mojca Kržan

\section{To cite this version:}

Katja Perdan-Pirkmajer, Janez Mavri, Mojca Kržan. Histamine (re)uptake by astrocytes: an experimental and computational study. Journal of Molecular Modeling, 2009, 16 (6), pp.1151-1158. 10.1007/s00894-009-0624-9 . hal-00568337

\section{HAL Id: hal-00568337 \\ https://hal.science/hal-00568337}

Submitted on 23 Feb 2011

HAL is a multi-disciplinary open access archive for the deposit and dissemination of scientific research documents, whether they are published or not. The documents may come from teaching and research institutions in France or abroad, or from public or private research centers.
L'archive ouverte pluridisciplinaire HAL, est destinée au dépôt et à la diffusion de documents scientifiques de niveau recherche, publiés ou non, émanant des établissements d'enseignement et de recherche français ou étrangers, des laboratoires publics ou privés. 


\section{Editorial Manager(tm) for Journal of Molecular Modeling Manuscript Draft}

Manuscript Number: JMM01024R1

Title: Histamine (re)uptake by astrocytes: an experimental and computational study

Article Type: Original paper

Keywords: histamine, transport, pKa, astrocytes, rat

Corresponding Author: Prof Mojca Krzan,

Corresponding Author's Institution:

First Author: Mojca Krzan

Order of Authors: Mojca Krzan; Katja Perdan-Pirkmajer; Janez Mavri

Abstract: Astrocytes participate in the clearance of neurotransmitters by their uptake and subsequent enzymatic degradation. Histamine as a polar and/or protonated molecule must use a carrier to be transported across the cell membrane, although a specific histamine transporter has not been elucidated, yet.

In this work we upgraded the kinetic studies of histamine uptake into neonatal rat cultured type 1 astrocytes with quantum chemical calculations of histamine pKa values in conjunction with Langevin dipoles solvation model as the first step toward microscopic simulation of transport.

Our results indicate that astrocytes transport histamine by at least two carrier mediated processes, a concentration gradient dependent passive and a sodium-dependent and ATP-driven active transport. We also demonstrated that histamine protonation states depend on the polarity of the environment.

In conclusion we suggest that histamine, a polar molecule at physiological $\mathrm{pH}$ uses at least two different mechanisms for its uptake into astrocytes -an electrodiffussion and $\mathrm{Na}+$-dependent and ouabain sensitive active process. We emphasize relevance of knowledge of histamines protonation states at the rate limiting step of its transport for microscopic simulation that will be possible when structure of histamine transporter is known.

Response to Reviewers:

Ljubljana, October 23, 2009

Dear Professor Sokalski,

Hereby I am resubmitting the manuscript entitled » Histamine (Re) uptake by Astrocytes: An Experimental and Computational Study" written by Katja Perdan-Pirkmajer, Janez Mavri and Mojca Kržan

First I would like to acknowledge very professional revision process. And please allow me to explain how we addressed the suggestions made by reviewers. All changes are highlighted in yellow 
Reviewer No 1:

Ad 1) to put the references $16-25$ in chronological order

As it is seen on page 19 and 20 we renumbered the referenced and wrote them chronologically. The change is highlighted.

Ad 2) page 6, paragraph 1 - we add the following text, which is highlighted in yellow within the main text.

"In the context of calculating the pKa values of flexible systems, it should be noted that the pKa is actually an average of all possible conformations of the protein. Kamerlin et al. ? 25? demonstrated that careful thermal averaging should be performed for both ionized and neutral states of the residue."

Ad 3) page 6

We deleted the sentence as suggested by reviewer.

Ad 4) instead on page 11 as suggested by reviewer, we changed the discussion by adding the following.

"An important message o this study and pKa calculations in general is that proper treatment of hydration is as important as the in vacuo energetics. This important issue is not properly understood by several theoretical chemists who want to explain enzymatic reactions by performing gas phase calculations. Consideration of the corresponding reaction in aqueous solution remains the most successful method of computational enzymology ? 46 ? ."

"The calculated pKa values are in the range between 16.7 and 12.8 and therefore they overestimate the experimental value of 9.4."

Reviewer No 2:

Ad General.

We did proof-reading and corrected all mistakes, misspellings and typing errors.

Ad 1. page 4, middle paragraph

We included the reference to Figure 3.

Ad 2. page 12, we rephrased the text as suggested by reviewer to

We add the following comment.

"The calculated pKa values are in the range between 16.7 and 12.8 and therefore they overestimate the experimental value of 9.4."

We are hoping that we meet the reviewers' expectations after rewriting the manuscript.

Sincerely, 


\title{
Histamine (Re) uptake by astrocytes: an experimental and computational study
}

Received: 16.09.2009 / Accepted: 05.11.2009

Katja Perdan-Pirkmajer ${ }^{1}$, Janez Mavri ${ }^{2}$ and Mojca Kržan ${ }^{1, \bigotimes}$

${ }^{1}$ Department of Pharmacology and Experimental Toxicology, Faculty of Medicine, University of Ljubljana, Korytkova 2, Si-1001 Ljubljana, Slovenia; katja.perdan@mf.uni-lj.si, mojca.limpel@mf.uni-lj.si

${ }^{2}$ National Institute of Chemistry, Hajdrihova 19, SI-1001 Ljubljana, Slovenia; janez.mavri@ki.si

${ }^{\circledR}$ Tel: +386 1543 7349; Fax: + 3861543 7331; Email: mojca.limpel@mf.uni-lj.si

Authors declare no conflict of interests.

\begin{abstract}
Astrocytes participate in the clearance of neurotransmitters by their uptake and subsequent enzymatic degradation. Histamine as a polar and/or protonated molecule must use a carrier to be transported across the cell membrane, although a specific histamine transporter has not been elucidated, yet.

In this work we upgraded the kinetic studies of histamine uptake into neonatal rat cultured type 1 astrocytes with quantum chemical calculations of histamine pKa values in conjunction with Langevin dipoles solvation model as the first step toward microscopic simulation of transport.

Our results indicate that astrocytes transport histamine by at least two carrier mediated processes, a concentration gradient dependent passive and a sodium-dependent and ATPdriven active transport. We also demonstrated that histamine protonation states depend on the polarity of the environment.
\end{abstract}


In conclusion we suggest that histamine, a polar molecule at physiological $\mathrm{pH}$ uses at least two different mechanisms for its uptake into astrocytes -an electrodiffusion and $\mathrm{Na}^{+}-$ dependent and ouabain sensitive active process. We emphasize relevance of knowledge of histamines protonation states at the rate limiting step of its transport for microscopic simulation that will be possible when structure of histamine transporter is known.

Keywords Histamine $\cdot$ Transport $\mathrm{pKa} \cdot$ Astrocytes $\cdot$ Rat 


\section{Introduction}

Histamine [2-(-imidazol-4-yl) ethylamine] belongs to a family of biogenic amines and is mostly known for its role as an inflammation mediator, neuromodulator and neurotransmitter. In the recent years it has gained importance as a signaling molecule in processes of sleepwake cycle, appetite control, learning, memory and emotion [1, 2], moreover, its signaling pathways seem to be involved in conditions such as depression, schizophrenia, Alzheimer's disease and epilepsy [2].

In the brain histamine is synthesized from histidine by a specific enzyme L-histidine decarboxylase (HD) [3] and is taken up into synaptic vesicles by the vesicular monoamine transporter 2 (VMAT2) [4]. It is released into synaptic cleft upon depolarization, which is followed by its removal from synaptic cleft in a relatively short time. The primary histamine metabolizing enzyme in the brain seems to be an intracellular histamine-N-methyltransferase (HNMT) [5]. Obviously, in order to be enzymatically degraded or recycled, histamine has to be transported either into the presynaptic neuron or into surrounding glial cells. Among glial cells astrocytes have been proposed to be the main histamine inactivation site [6]. Reports from Huszti's laboratory described bidirectional [7-9] histamine uptake into cultured glial cells prepared from embryonic chicks [7] and neonatal rats [8-10] which was $\mathrm{Na}^{+}$-but not $\mathrm{Cl}^{-}$dependent [11]. Glial cells were also found to be involved in the continuous removal of neuronal histamine from the synaptic cleft in in vivo conditions [12]. In our previous work, we suggested that histamine is taken up into cultured neonatal rat astrocytes by at least two different transport systems [13]. A high affinity, low capacity, energy- and temperaturedependent transport system and a low affinity, high capacity system which shows little energy and temperature dependence and shares some similarities with uptake 2 .

When discussing histamine transport through physiological barriers, one should keep in mind that histamine can be double protonated with pKa values of 5.8 (imidazole ring nitrogen atom) and 9.4 (aliphatic primary amine nitrogen atom) [14]. Therefore, at physiological pH histamine exists as an equilibrium mixture of tautomeric cations, with monocation making approximately $96 \%$ and dication $3 \%$ and only small amount of nonprotonated species [15].

Structures of histamine tautomers are show in Fig. 3. Being protonated, it cannot freely cross membranes but needs a carrier protein, which has not been elucidated yet. In order to better understand characteristics of histamine transport it is essential to properly model the protonation states, in particular properties of histamine at physiological conditions, when 
transported histamine molecule is moving through environments of different polarity. It is expected that the protonation states of histamine will change during the process and it is essential for the transport to evaluate free energy differences associated with protonation and deprotonation.

Protonation states are difficult to study experimentally. When studying the protonation states in different environments it is firstly necessary to critically examine how different computational methods perform in aqueous solution for which pKa values are already known. Much effort has been spent recently on pKa values calculations [16-25]. Computational practice has proved that in vacuo energetics can be obtained by using high level quantum chemical calculations corrected for zero-point vibrational energy which is typically calculated in harmonic approximation. A general rule is that flexible basis should be used in conjunction with correlated wave function. Density functional theory (DFT) methods represent an attractive alternative [26, 27]. As important as in vacuo energetics is evaluation of hydration energies for different species. Critical value is hydration free energy of ionic species. If one is only looking $\mathrm{pKa}$ values relative to other Brønsted acids then the error of hydration free energy for hydronium ion is the same for all the acids and the cation hydration free energy remains a critical component. Since calculation of proton hydration free energy is demanding and subject of significant uncertainty, consideration of its experimental value is a reasonable choice when calculating $\mathrm{pKa}$ values. Experimentally free energy for transfer of $\mathrm{H}^{+}$from gas phase to aqueous solution is determined more accurately than hydration free energy of hydronium ion. Former value includes formation of hydronium ion. It is interesting that the reported experimental values for proton transfer to from gas phase to the aqueous solution span a wide range e.g. $-252.4 \mathrm{kcal} \mathrm{mol}^{-1}$ [28], $-259.2 \mathrm{kcal} \mathrm{mol}^{-1}$ [29]. The later is an average of values obtained from measurements of standard hydrogen potentials in the range from 253.6 to $-260.8 \mathrm{kcal} \mathrm{mol}^{-1}$. The most recent cluster ion solvation data suggest a hydration free energy of $-264 \mathrm{kcal} \mathrm{mol}^{-1}$ [30], which we used for calculations of histamine pKa values.

Duarte's group [31] carefully examined $\mathrm{pKa}$ values of histamine by using solvent reaction field in conjunction with several flexible basis sets on Hartree-Fock (HF), Møller-Plesset perturbational theory of the second order (MP2) and various DFT levels. The authors emphasized the difficulty to predict $\mathrm{pKa}$ value relative to water because of poor performance of the methods to predict hydration free energy of the hydronium ion. Therefore their calculated pKa values were relative to acetate and a reasonable agreement with the experiment was found. Protonation states and therewith associated $\mathrm{pKa}$ values are relevant for enzyme catalysis [32]. Hudaky and Perczel [33] recently performed careful calculations 
concerning protonation states of histidine involved in catalytic triad of serine proteases. They stressed relevance of conformational changes for $\mathrm{pKa}$ values. In the context of calculating the $\mathrm{pKa}$ values of flexible systems, it should be noted that the pKa is actually an average of all possible conformations of the protein. Kamerlin et al. [25] demonstrated that careful thermal averaging should be performed for both ionized and neutral states of the residue.

To establish whether different protonation states of histamine affect the features of its electrodiffusion and active transport across the cell membrane, we combined uptake kinetic studies with calculation of pKa values of histamine by applying Langevin dipoles (LD) of Florian and Warshel [34-36]. We also critically examined the existing computational methods for calculation of $\mathrm{pKa}$ values in aqueous solution. Protonation states were discussed in the context of different environmental polarities histamine faces during the transport.

\section{Materials and methods}

\section{Materials}

All tissue culture reagents, except fetal bovine serum (Cambrex, Belgium) were obtained from GIBCO, Great Britain. $\left[{ }^{3} \mathrm{H}\right]$-histamine $\left(525.4 \mathrm{GBq} \mathrm{mmol}^{-1}\right)$ was purchased from Perkin Elmer, USA.

\section{Astrocyte culture}

Rats were used in accordance with the National Institutes of Health Guidelines for the Care and Use of Laboratory Animals and Permission for Use of Laboratory Animals 323-02232/2005/2 and 34401-81/2008/5 issued by Veterinary Administration of Republic of Slovenia. Astrocyte cultures were prepared from the cortex of neonatal Wistar rats (3 days old, both sexes) and cultured as previously described [37]. Briefly, cells were grown in highglucose Dulbecco's modified Eagle's medium (DMEM), containing $10 \%$ fetal bovine serum (FBS), $1 \mathrm{mM}$ pyruvate, $2 \mathrm{mM}$ glutamine, and $25 \mu \mathrm{g} \mathrm{ml}^{-1}$ gentamycin in $95 \%$ air $-5 \% \mathrm{CO}_{2}$. Confluent cultures were shaken at $225 \mathrm{rpm}$ overnight, and the medium was changed the next morning; this was repeated a total of three times. After the third overnight shaking, the cells were trypsinized and cultured for $24 \mathrm{~h}$ in $10 \mu \mathrm{M}$ cytosine arabinoside. After reaching 
confluence again the cells were subcultured into 12-well clusters and grown for additional 3 weeks.

\section{Uptake of $\left[{ }^{3} \mathrm{H}\right]$-histamine into cultured astrocytes}

Monolayer cultures in 12-well clusters were preincubated for $30 \mathrm{~min}$ in uptake buffer $(25 \mathrm{mM}$ HEPES, $125 \mathrm{mM} \mathrm{NaCl}, 4.8 \mathrm{mM} \mathrm{KCl}, 1.2 \mathrm{mM} \mathrm{KH}_{2} \mathrm{PO}_{4}, 1.2 \mathrm{mM} \mathrm{MgSO}_{4}, 1.4 \mathrm{mM} \mathrm{CaCl}_{2}$, and $5.6 \mathrm{mM}$ glucose, $\mathrm{pH} 7.4$ ) at $37{ }^{\circ} \mathrm{C}$ (total uptake) and at $4{ }^{\circ} \mathrm{C}$ (non-specific uptake). After preincubation the histamine transport was initialized by addition of radiolabeled histamine, the final radioligand concentration being $0.125 \mu \mathrm{M}-100 \mu \mathrm{M}$ for the dose response curve and $0.125 \mu \mathrm{M}$ for other experiments. After $20 \mathrm{~min}$ the reaction was stopped by placing the dishes into an ice-water bath. The buffer was quickly removed and the dishes were washed twice with ice-cold uptake buffer. The cells were lysed in $0.6 \mathrm{~mL}$ of $0.5 \mathrm{M} \mathrm{NaOH}$. $0.5 \mathrm{~mL}$ of each sample was transferred to a scintillation vial and the radioactivity was measured. Protein content was determined in the remaining aliquots $(0.1 \mathrm{ml})$ using Bio-Rad method. To determine the effect of $\mathrm{Na}^{+}$on histamine uptake, $\mathrm{NaCl}$ in the uptake buffer was replaced with choline chloride. The activity of $\mathrm{Na}^{+} \mathrm{K}^{+} \mathrm{ATP}$-ase was inhibited by adding $1 \mathrm{mM}$ ouabain .

\section{Data analysis}

The uptake experiments were routinely carried out in triplicates and each experiment was repeated twice. The results are expressed as means \pm SEM. The kinetic parameters $(\mathrm{Km}$ and Vmax) were calculated by a non-linear regression method using software Prism4 version 4.00 (GraphPad Software Inc., San Diego, USA). Comparison of data among groups was carried out using independent samples t-test. Differences were considered significant at $\mathrm{P}<0.05$.

\section{Computational methods}

All calculations were performed at the National Institute of Chemistry in Ljubljana on the eight processor CHIEFTEC Linux-based personal computer. Series of ab initio and DFT calculations encoded in the Gaussian03 suite of programs had been applied. A full geometry optimization was performed for all the species. We limited our study to two basis sets $6-31+\mathrm{G}$ $(\mathrm{d}, \mathrm{p})$ and $6-31++\mathrm{G}(2 \mathrm{~d}, 2 \mathrm{p})$. Former basis set is double zeta and is augmented with polarization functions of heavy atoms and hydrogen atoms and additionally contains diffuse 
functions on heavy atoms. To the latter basis set are added diffuse functions to hydrogen atoms and polarization functions to heavy atoms and hydrogen atoms.

$A b$ initio calculations were performed on the HF level of theory. In order to include some electron correlation we applied Møller-Plesset perturbation of the second order. Moreover, we applied DFT method B3LYP. The DFT method B3LYP, has the Becke three parameter hybrid gradient-corrected exchange functional [26], combined with the gradient-corrected correlation functional of Lee, Yang and Parr [27]. Same basis sets as for HF level of theory were also used for the B3LYP for the species mentioned above. Full geometry optimization was performed for all the species and vibrational analysis was performed in the harmonic approximation.

The LD by Florian and Warshel [34-36] was used to calculate the solvation free energies for all the species. The Merz-Kollman partial atomic charges also encoded in the Gaussian03 served us as an input for the LD model that was later built in the ChemSol 2.1 program [34, 35]. In the LD procedure hydration free energy is calculated as reversible work necessary to build a solute charge distribution in the field of dipoles on a cubic grid. The charge distribution is represented by Merz-Kollman atomic charges and thermal averaging is performed by charging the coordinate origin.

\section{Results}

\section{$\mathrm{Na}^{+}$-dependence and ouabain sensitivity}

Astrocytes were prepared from cortices of neonatal rats (postnatal day 3) as previously described [11]. At that point, the cultures contained 93-100\% type 1 astrocytes, determined by immunochemical staining for glial fibrillary acidic protein [37]. Since the time course of histamine uptake has already been reported in our recent paper [13], we proceeded with experiments concerning sodium dependence and ouabain sensitivity. Fig. 1 presents the influence of $\mathrm{Na}^{+}$replacement with choline and ouabain treatment of cultured astrocytes at two different temperatures. The depletion of $\mathrm{Na}^{+}$in cultured medium resulted in a significant decrease of histamine uptake by cultured astrocytes at $37{ }^{\circ} \mathrm{C}$, whereas no $\mathrm{Na}^{+}$-dependence of histamine uptake was measured at $4{ }^{\circ} \mathrm{C}$. The addition of ouabain affected only histamine 
uptake into cultured astrocytes at $37{ }^{\circ} \mathrm{C}$ and had no effect on its transport into astrocytes at 4 ${ }^{\circ} \mathrm{C}$ (Fig. 1).

$<$ Fig. 1>

\section{Concentration-dependent histamine uptake}

Further on, we determined the kinetic properties of histamine uptake (Fig. 2). Cultured astrocytes were incubated for 20 min with ${ }^{3} \mathrm{H}$-histamine in a concentration range from $0.125-$ $90 \mu \mathrm{M}$ at $37{ }^{\circ} \mathrm{C}$ (total uptake) and $4{ }^{\circ} \mathrm{C}$ (non-specific uptake). Histamine was taken up in a concentration-dependent manner (Fig. 2) at both temperatures used. The specific histamine transport represents the difference between the total $\left(37^{\circ} \mathrm{C}\right)$ and the non-specific one $\left(4{ }^{\circ} \mathrm{C}\right)$. The kinetic analysis of specific histamine transport calculated by non-linear regression analysis revealed Michaelis constant $(\mathrm{Km})$ of $5.2 \pm 2.1 \mu \mathrm{M}$ of and maximal rate (Vmax) of $11.2 \pm 1.0 \mathrm{pmol} \mathrm{mg}{ }^{-1}$ protein/min (Fig. 2, insert).

<Fig. 2>

\section{Quantum chemical calculations}

Quantum chemical calculations in conjunction with free energies of hydration yield free energies of different protonation states. Calculated energies of both neutral tautomers of histamine are collected in Table 1 . On all levels of theory the $\alpha$ form is predicted to be more stable in the gas phase for about $0.6 \mathrm{kcal} \mathrm{mol}^{-1}$. Inclusion of solvent decreases the free energy difference but the $\alpha$ form is still more stable. The free energy differences are in the range 0.05 kcal $\mathrm{mol}^{-1}\left(\mathrm{HF} / 6-31 \mathrm{G}(\mathrm{d}, \mathrm{p})\right.$ level to $0.56 \mathrm{kcal} \mathrm{mol}^{-1}$ (MP2/6-31G(d,p)), what gives strong evidence that both neutral forms are present. This fact can be used when interpreting experimental data such as spectra that are superpositions of both components.

$<$ Table 1>

Table 2 presents the calculated energetics associated with the first pKa value of histamine. The first deprotonation step is proton transfer from the aliphatic protonated amino group of the single charged histamine to a water molecule giving rise to neutral histamine and hydronium ion. In vacuo energetics gives evidence that in the gas phase this is an endothermic process associated with about $220 \mathrm{kcal} \mathrm{mol}^{-1}$ energy difference. Hydration reduces this gap 
for about $205 \mathrm{kcal} \mathrm{mol}^{-1}$, giving rise to $20 \mathrm{kcal} \mathrm{mol}^{-1}$ free energy difference. The calculated $\mathrm{pKa}$ values are in the range between 16.7 and 12.8 and therefore they overestimate the experimental value of 9.4 .

$<$ Table 2>

Table 3 is collected the energetics associated with the second pKa value of histamine. The second deprotonation step is transfer of the proton from the imidazole nitrogen atom of the double charged histamine to a water molecule giving rise to monoprotonated histamine at aliphatic amino group and hydronium ion. In contrast to the first deprotonation step already the gas phase energetics favors this process. The gas phase reaction is exothermic on all levels of theory. The convergence in terms of the level of theory is poorer than for the first deprotonation step. Hydration in this case favors the process for approximately $140 \mathrm{kcal} \mathrm{mol}^{-}$ ${ }^{1}$. The entire process in terms of free energy is uphill for about 9-16 kcal mol ${ }^{-1}$, giving rise to $\mathrm{pKa}$ values of 6.7-12.2. Inspection of Tables 2 and 3 gives confidence that calculation of $\mathrm{pKa}$ values on MP2 level in conjunction with flexible basis sets is reliable enough to proceed with replacement of aqueous solution with protein environment.

$<$ Table $3>$

In order to critically examine the quality of the applied solvation model, we collected the free energies of solvation for different species in Table 4. It is clearly evident that the calculated hydration free energy of hydronium ion is not favorable and is the dominant source of the too high pKa values. Therefore, our strategy to consider the experimental hydration free energy of a proton is fully justified. Zhan and Dixon emphasized the difficulty to properly measure and calculate hydronium and hydroxide ion hydration free energy [38]. Some authors avoided this difficulty by considering other Brønsted basis as a water molecule giving rise to relative $\mathrm{pKa}$ values [31]. The structures of various histamine tautomers are presented in Fig. 3.

$<$ Table 4>

<Fig. 3> 


\section{Discussion}

Histamine acts as a neurotransmitter only in the mature rat brain and as neuromodulator and growth promoting agent in the neonatal rat brain. Regardless the fact that histamine probably adopts its role as a classical signaling molecule not earlier than by postnatal day 20 [39], it is also taken up into neonatal rat astrocytes with a half time of $1.3 \mathrm{~min}$ [13] that is similar to its blood inactivation time of $0.5-3.5 \mathrm{~min}$ [40, 41]. In addition, astrocytes express mRNA for HNMT, histamine degrading enzyme [13, 42], which supports the notion that uptake and subsequent metabolism by glial cells of released histamine from neurons may play important role in regulating extracellular histamine concentration.

Astrocytes most probably represent the main histamine inactivation site within CNS. They take up significantly more histamine than synaptosomes [43] and shake off cells (mixture of microglia, oligodendrocytes, $\mathrm{O} 2$ progenitor cells and type 2 astrocytes) [11]. Fig. 1 shows that the replacement of sodium chloride in the incubation medium with choline chloride or ouabain treatment significantly, but not completely decrease histamine uptake into cultured neonatal rat astrocytes at $37{ }^{\circ} \mathrm{C}$. This reconfirms our previous finding [13] concerning the involvement of the two different transport pathways, active and passive one by which histamine is carried into astrocytes at $37{ }^{\circ} \mathrm{C}$. The transport of histamine into shake off cells is probably electrodiffusion, as it seems not to be affected neither by lack of sodium ions in the incubation medium nor by ouabain treatment [11]. The same phenomenon (electrodiffusion, a process that depends on concentration gradient and membrane potential) might explain the process by which histamine accumulates within astrocytes at $4{ }^{\circ} \mathrm{C}$, which demonstrates concentration dependence [11], but no $\mathrm{Na}^{+}$-dependence or ouabain sensitivity (Fig.1). Saturation profile at $4^{\circ} \mathrm{C}$ suggests presence of a limited number of carrier proteins, that allow just for finite flux and not a simple diffusion process as one might expect. More than one transport pathway probably serves as backup mechanism for situations where high affinity transporter proteins are underrepresented or overloaded.

Carrier-operated histamine uptake into cultured rat type 1 astrocytes revealed the $\mathrm{Km}$ value of $5.2 \pm 2.1 \mu \mathrm{M}$ and Bmax of $11.2 \pm 1.0 \mathrm{pmol} \mathrm{mg}^{-1}$ protein/min (Fig. 2). The measured $\mathrm{Km}$ value was significantly higher than Km obtained by Huszti et al. [8] - $0.19 \mu \mathrm{M}$ in astrocytes and $0.30 \mu \mathrm{M}$ in rat cerebral endothelial cells [43], but similar to the $\mathrm{Km}$ value of histamine uptake in the P2 fraction of rat synaptosomes [44]. Histamine is a known substrate for organic cation transporters (OCTs) and cultured rat astrocytes express OCT1, OCT2 and OCT3 [45] that transport monoamines in such manner. Nevertheless, the Km values for histamine transport 
by OCTs are significantly different $(180-940 \mu \mathrm{M})$ [44] than the affinity for histamine uptake obtained in our study, so the observed carrier(s) seem(s) to represent a new entity. It remains a major challenge for structural biology to determine the structure of histamine carrier that will pave way to understanding the transport on a molecular level. Active, ATP-driven component of histamine uptake is highly temperature dependent. As such, it is obviously a process that involves soft modes and is entropy sensitive. To understand the nature of histamine uptake, which includes the temperature dependence, future studies will involve sine dubio fine interplay between experimental work and molecular simulation. The latter will require all atom simulation including the transport protein, water and it will be performed in conjunction with chemically reactive species.

While being carried from extracellular to intracellular space histamine molecule is moving through environments of different polarity. We calculated stabilities of two neutral tautomers of histamine and absolute histamine $\mathrm{pKa}$ values by using ab initio calculations on HF, MP2 and B3LYP level with flexible basis sets in conjunction with LD solvation model. For the neutral form the $\alpha$ tautomer was predicted to be more stable on all applied levels of theory, although the free energy difference is small enough to allow both tautomers to be present and this should be considered when interpreting the experimental data. We analyzed the (free) energy contributions to both histamine pKa values. Moreover, by calculating hydration free energy by LD one is considering all hydration layers around neutral histamine and both protonated forms. Polarity of the interior of the transport protein is different from the polarity of the extracellular as well as the polarity of the cytoplasm. Thus, the protonation states of histamine will presumably change during the transport process. Histamine can be transported in a neutral form or in any of the protonated forms, where $\mathrm{pKa}$ is a measure of probability of the protonation states. Our calculations suggest that addition of the second proton in the gas phase is less favorable than addition of the first one. The reduced affinity can be attributed to the repulsion between proton and monoprotonated cation.

An important message of this study and pKa calculations in general is that proper treatment of hydration is as important as the in vacuo energetics. This important issue is not properly understood by several theoretical chemists who want to explain enzymatic reactions by performing gas phase calculation. Consideration of the corresponding reaction in aqueous solution remains the most successful method of computational enzymology [16]. 


\section{Summary}

We can conclude that histamine; a polar molecule at physiological $\mathrm{pH}$ cannot move freely across cell membrane and as such is taken up into neonatal astrocytes by two different processes - an electrodiffusion and an active, $\mathrm{Na}^{+}$-dependent and ouabain sensitive process. One must keep in mind that histamine protonation state at the selectivity filter or at the rate limiting step of the histamine transport, such as any transporter involved, is of high relevance for design of the analogs that may act as histamine uptake inhibitors. When structure of histamine transporter is determined, histamine protonation studies will help to clarify the transport mechanisms as well as provide foundation for drug design. We expect that studies of histamine transport will contribute to better understanding of various neurological disorders and their future treatment development.

\section{Acknowledgments}

We would like to thank Mrs. Jožica Košir for excellent technical assistance. Financial support from Slovenian Agency for Research through grants P3-067, P1-012 and J1-2014 is gratefully acknowledged. 


\section{References}

1. Passani MB, Giannoni P, Bucherelli C, Baldi E, Blandina P (2007) Histamine in the brain: beyond sleep and memory. Biochem Pharmacol 73:1113-1122

2. Tashiro M, Yanai K (2007) Molecular imaging of histamine receptors in human brain. Brain Nerve 59:221-231

3. Kataoka K, Roberts E (1967) Histamine in isolated small nerve endings and synaptic vesicles of rat brain cortex. J Pharmacol Exp Ther 156:114-125

4. Merickel A, Edwards H (1995) Transport of histamine by vesicular monoamine trasporter-2. Neuropharmacol 34:1543-1547

5. Tuomisto L, Tuomisto J (1982) Diurnal variations in brain and pituitary histamine and histamine-N-methyltransferase in the rat and guinea pig. Med Biol 60:204-209

6. Rafalowska U, Waskiewicz J, Albrecht J (1987) Is neurotransmitter histamine predominantly inactivated in astrocytes? Neurosci Lett 80:106-110

7. Huszti Z, Rimanóczy A, Juhasz A, Magyar K (1990) Uptake, metabolism, and release of $\left[{ }^{3} \mathrm{H}\right]$-histamine by glial cells in primary cultures of chicken cerebral hemispheres. Glia $3: 159-168$

8. Huszti Z (1994) Mechanism and function of histamine-sodium cotransport by astroglial cells. Agents and Actions 41:C58-59

9. Huszti Z (1998) Carrier-mediated high affinity uptake system for histamine in astroglial and cerebral endothelial cells. J Neurosci Res 51:551-558

10. Huszti (2003) Histamine uptake into non-neuronal brain cells. Inflamm Res 52:S03-06

11. Kržan M, Schwartz JP (2006) Histamine transport in neonatal and adult astrocytes. Inflamm Res 55:S36-37

12. Huszti Z, Prast H, Tran MH, Fischer H, Philippu A (1998) Glial cells participate in histamine inactivation in vivo. Naunyn Schmiedeberg's Arch Pharmacol 357:49-53

13. Osredkar D, Burnik-Papler T, Pečavar B, Kralj-Iglič V, Kržan M (2009) Kinetic and pharmacological properties of ${ }^{3}[\mathrm{H}]$-histamine transport into cultured type 1 astrocytes from neonatal rats. Inflamm Res 58:94-102

14. Cooper DG, Young RC, Durant GJ (1990) Histamine receptors. In: Emmet (ed) Comprehensive Medicinal Chemistry, the Rational Design, Mechanistic Study, and Therapeutic Application of Chemical Compounds vol 3: Membranes and Receptors. Pergamon Press, Oxford, pp 343-421 
15. Nelson WL (2008) Antihistamines and related antiallergic and antiulcer agents. In: Lemke TL, Williams DA, Roche VF, Zito SW (eds) Foye's Principles of Medicinal Chemistry, Lippincot, William and Willkin, Baltimore, pp 1004-1025

16. Warshel A (1981) Calculations of enzymatic reactions: calculations pKa, proton transfer reactions, and general acid catalysis reactions in enzymes. Biochem 20:3167-3177

17. Miertus S, Scrocco E, Tomasi J (1981) Electrostatic interaction of a solute with a continuum. A direct utilization of ab initio molecular potentials for the prevision of solvent effects. Chem Phys 55:117-129

18. Bashford D, Karplus M (1990) pKa's of ionizable groups in proteins: atomic detail from a continuum electrostatic model? Biochem 29:10219-10225

19. Misra VK, Honig B (1995) On the magnitude of the electrostatic contribution to ligandDNA interactions. Proc Natl Acad Sci 92:4691-4695

20. McCammon JA, Nielsen JE (2003) Calculating pKa values in enzyme active sites. Protein Sci 12:1894-1901

21. Li G, Cui Q (2003) pKa calculations with combined QM/MM free energy perturbations. J Phys Chem B 107:14521-14528

22. Vianello R, Maksić ZB (2004) The acidity of Brønsted CH acids in DMSO - the extreme acidity of nonacyanocyclononatetraene. Eur J Org Chem 24:5003-5010

23. Riccardi D, Cui Q (2007) pKa analysis for the zinc-bound water in human carbonic anhydrase II: benchmark for "multi-scale" QM/MM simulations and mechanistic implications. J Phys Chem 111:5703-5711

24. Ghosh N, Cui Q (2008) pKa of residue 66 in Staphylococal nuclease. I. Insights from QM/MM simulations with conventional sampling. J Phys Chem 112:8387-8397

25. Kamerlin SCL, Haranczyk M, Warshel A (2009) Progress in ab initio QM/MM free energy simulations of electrostatic energies in proteins: accelerated QM/MM studies of pKa, redox reactions and solvation free energies. J Phys Chem113:1253-1272

26. Becke AD (1993) Density-functional thermochemistry. The role of exact exchange. J Chem Phys 98:5648-5652

27. Lee C, Yang W, Parr RG (1988) Development of the Colle-Salvetti correlation-energy formula into a functional of the electron density. Phys Rev 37:785-789

28. Marcus Y (1985) Ion salvation, Wiley, New York

29. Lim C, Bashford D, Karplus M (1991) Absolute pKa calculations with continuum dielectric methods. J Phys Chem 95:5610-5620 
30. Tissandier MD, Cowen KA, Feng WY, Gundlach E, Cohen MH, Earhart AD, et al (1998) The proton's absolute aqueous enthalpy and Gibbs free energy of solvation from clusterion solvation data. J Phys Chem A102:7787-7794

31. Abreu HA, Almedia WB, Duarte HA (2004) pKa calculation of polyprotic acid: histamine. Chem Phys Lett 383:47-52

32. Henderson Pozzi M, Gawandi V, Fitzpatrick PF (2007) pH dependence of a mammalian polyamine oxidase: insights into substrate specificity and the role of lysine 315 . Biochemistry 48:1508-1516

33. Hudaky P, Perczel A (2007) pKa optimized catalysis in serine proteinases, an ab initio study on the catalytic His. Int J Quant Chem 107:2178-2183

34. Florian J, Warshel A (1999) Calculations of hydration entropies of hydrophobic, polar, and ionic solutes in the framework of the Langevin dipoles solvation model. J Phys ChemB 103:10282-10288

35. Florian J, Warshel A (1997) Langevin dipoles model for ab initio calculations of chemical processes in solution: Parametrization and application to hydration free energies of neutral and ionic solutes and conformational analysis in aqueous solution. J Phys Chem B 101:5583-5595

36. Strajbl M, Florian J, Warshel A (2000) Ab initio evaluation of the potential surface for general base-catalyzed methanolysis of formamide: a reference solution reaction for studies of serine proteases. J Am Chem Soc 122:5354-5366

37. Schwartz JP, Wilson DJ (1992) Preparation and characterization of type 1 astrocytes cultured from adult rat cortex, cerebellum and striatum. Glia 5:75-80

38. Zhan CG, Dixon DA (2002) First-principles determination of the absolute hydration free energy of the hydroxide ion. J Phys Chem 106:9737-9744

39. Hough LB, Khandelwal JK, Green JP (1982) Ontogeny and subcellular distribution of rat brain tele-methylhistamine. J Neurochem 38:1593-1599

40. Ferreira SH, Ng KK, Vane JR (1973) The continuous bioassay of the release and disappearance of histamine in the circulation. Br J Pharmacol 49:543-553

41. Belič A, Grabnar I, Karba R, Mrhar A, Irman-Florjanc T, Primožič S (1999) Interdependence of histamine and methylhistamine kinetics: modelling and simulation approach. Comput Biol Med 29:361-375

42. Garbarg M, Baudry M, Benda O, Schwartz JC (1975) Simultaneous presence of histamine-N-methyltransferase and catehol-O-methyl-transferase in neuronal and glial cells in culture. Brain Res 83:1539-1539 
43. Sakurai E, Sakurai E, Oreland L, Nishiyama S, Kato M, Watanabe T, et al (2006) Evidence for the presence of histamine uptake into the synaptosomes of rat brain. Pharmacology 78:72-80

44. Huszti Z, Balogh I (1995) Effects of lead and mercury on histamine uptake by glial and endothelial cells. Pharmacol Toxicol 76:339-342

45. Inazu M, Taheda H, Matsumiya $\mathrm{T}$ (2005) Molecular and functional characterization of an $\mathrm{Na}^{+}$-independent choline transporter in rat astrocytes. J Neurochem 94:1427-1437 
Table 1 Stabilities of tautomers of neutral histamine. All energies are in $\mathrm{kcal} \mathrm{mol}^{-1}$ relative to $\alpha$ tautomer. E is classical energy difference. ZPE stands for zero point energy correction. $\mathrm{E}_{\text {dry }}$ is sum of $\mathrm{E}$ and $\mathrm{ZPE} . \Delta \mathrm{G}_{\mathrm{hydr}}$ is hydration contribution to this process and total free energy difference. $\Delta \mathrm{G}$ stands for free energy of hydration plus $\mathrm{E}_{\mathrm{dry}}$

\begin{tabular}{|c|c|c|c|c|c|}
\hline Method & $\mathrm{E}$ & $\mathrm{ZPE}$ & $\mathrm{E}_{\mathrm{dry}}$ & $\Delta \mathrm{G}_{\mathrm{hydr}}$ & $\Delta \mathrm{G}$ \\
\hline $\mathrm{HF} / 6-31 \mathrm{G}(\mathrm{d}, \mathrm{p})$ & 0.51 & 0.08 & 0.59 & -0.54 & 0.05 \\
\hline HF/6-31++G(2d,2p) & 0.45 & 0.09 & 0.54 & -0.49 & 0.05 \\
\hline B3LYP/6-31+G(d,p) & 0.52 & 0.07 & 0.59 & 0.59 & 0.19 \\
\hline $\begin{array}{c}\text { B3LYP/6- } \\
\text { 31+G(2d,2p) }\end{array}$ & 0.53 & 0.07 & 0.60 & 0.60 & 0.15 \\
\hline $\mathrm{MP} 2 / 6-31+\mathrm{G}(\mathrm{d}, \mathrm{p})$ & 0.69 & 0.06 & 0.75 & 0.75 & 0.56 \\
\hline MP2/6-31+G(2d,2p) & 0.53 & 0.09 & 0.62 & 0.62 & 0.33 \\
\hline
\end{tabular}


Table 2 The first pKa value for histamine calculated on different levels of theory in conjunction with Langevin dipoles solvation model. The calculated $\mathrm{pKa}$ value is for the process where monoprotonated histamine donates a proton to a water molecule. All values are in $\mathrm{kcal} \mathrm{mol}^{-1}$. E is classical energy difference for the process. ZPE stands for zero point energy correction. $\mathrm{E}_{\mathrm{dry}}$ is sum of $\mathrm{E}$ and $\mathrm{ZPE} . \Delta \mathrm{G}_{\mathrm{hydr}}$ is hydration contribution to this process and $\Delta \mathrm{G}=\mathrm{E}_{\text {dry }}+\Delta \mathrm{G}_{\text {hydr. }} \mathrm{pKa}^{(1)}=\Delta \mathrm{G} /\left(\ln (10) \mathrm{k}_{\mathrm{B}} \mathrm{T}\right)$ Note that the experimental value for proton hydration free energy of $-264 \mathrm{kcal} \mathrm{mol}^{-1}$ was used

\begin{tabular}{|c|c|c|c|c|c|c|}
\hline Method & $\mathrm{E}$ & $\mathrm{ZPE}$ & $\mathrm{E}_{\mathrm{dry}}$ & $\Delta \mathrm{G}_{\mathrm{hydr}}$ & $\Delta \mathrm{G}$ & $\mathrm{pKa}^{(1)}$ \\
\hline $\mathrm{HF} / 6-31 \mathrm{G}(\mathrm{d}, \mathrm{p})$ & 237.52 & -10.22 & 227.30 & -204.67 & 22.63 & 16.7 \\
\hline HF/6-31++G(2d,2p) & 237.50 & -10.25 & 227.25 & -204.44 & 22.81 & 16.8 \\
\hline B3LYP/6-31+G(d,p) & 233.48 & -9.64 & 223.84 & -205.24 & 18.60 & 13.7 \\
\hline B3LYP/6-31++G(2d,2p) & 233.02 & -9.61 & 223.41 & -204.98 & 18.43 & 13.6 \\
\hline MP2/6-31+G(d,p) & 234.37 & -9.79 & 224.58 & -205.38 & 19.20 & 14.1 \\
\hline MP2/6-31++G(2d,2p) & 232.34 & -9.73 & 222.62 & -205.25 & 17.37 & 12.8 \\
\hline Experimental value & & & & & 12.77 & 9.4 \\
\hline
\end{tabular}


Table 3 The second $\mathrm{pKa}$ value for histamine calculated on different levels of theory in conjunction with Langevin dipoles solvation model. The calculated $\mathrm{pKa}$ value is for the process where diprotonated histamine donates a proton to a water molecule giving rise to monoprotonated form and hydronium ion. All values are in $\mathrm{kcal} \mathrm{mol}^{-1}$. $\mathrm{E}$ is classical energy difference for the process. ZPE stands for zero point energy correction. $\mathrm{E}_{\mathrm{dry}}$ is sum of $\mathrm{E}$ and ZPE. $\Delta \mathrm{G}_{\text {hydr }}$ is hydration contribution to this process and $\Delta \mathrm{G}=\mathrm{E}_{\mathrm{dry}}+\Delta \mathrm{G}_{\text {hydr. }} \mathrm{pKa}^{(2)}=\Delta \mathrm{G} /$ $\left(\ln (10) k_{B} T\right)$. Note that the experimental value for proton hydration free energy of $-264 \mathrm{kcal}$ mol $^{-1}$ was used

\begin{tabular}{|c|c|c|c|c|c|c|}
\hline Method & $\mathrm{E}$ & $\mathrm{ZPE}$ & $\mathrm{E}_{\mathrm{dry}}$ & $\Delta \mathrm{G}_{\mathrm{hydr}}$ & $\Delta \mathrm{G}$ & $\mathrm{pKa}^{(2)}$ \\
\hline $\mathrm{HF} / 6-31 \mathrm{G}(\mathrm{d}, \mathrm{p})$ & 165.68 & -9.07 & 156.61 & -140.05 & 16.56 & 12.2 \\
\hline $\mathrm{HF} / 6-31++\mathrm{G}(2 \mathrm{~d}, 2 \mathrm{p})$ & 165.57 & -9.06 & 156.51 & -139.40 & 17.11 & 12.6 \\
\hline B3LYP/6-31+G(d,p) & 160.62 & -8.61 & 152.01 & -139.67 & 12.34 & 9.1 \\
\hline B3LYP/6-31++G(2d,2p) & 160.76 & -8.62 & 152.14 & -139.11 & 13.03 & 9.6 \\
\hline MP2/6-31+G(d,p) & 158.58 & -8.65 & 149.93 & -139.99 & 9.94 & 7.3 \\
\hline MP2/6-31++G(2d,2p) & 156.97 & -8.59 & 148.38 & -139.32 & 9.06 & 6.7 \\
\hline Experimental value & & & & & 7.88 & 5.8 \\
\hline
\end{tabular}


Table 4 Free energies of hydration calculated by Langevin dipoles solvation model. All values are in $\mathrm{kcal} \mathrm{mol}^{-1}$. $\mathrm{N \alpha}$ is $\alpha$ tautomer neutral form of histamine. PROT1 is monoprotonated at amino nitrogen atom form and PROT 2 is a double protonated form

\begin{tabular}{|c|c|c|c|c|c|}
\hline Method & $\mathrm{N} \alpha$ & PROT1 & PROT2 & $\mathrm{H}_{3} \mathrm{O}^{+}$ & $\mathrm{H}_{2} \mathrm{O}$ \\
\hline $\mathrm{HF} / 6-31 \mathrm{G}(\mathrm{d}, \mathrm{p})$ & -10.58 & -69.91 & -193.86 & -97.27 & -8.44 \\
\hline $\mathrm{HF} / 6-31++\mathrm{G}(2 \mathrm{~d}, 2 \mathrm{p})$ & -9.97 & -69.53 & -194.13 & -97.26 & -6.94 \\
\hline B3LYP/6-31+G(d,p) & -9.79 & -68.55 & -192.88 & -96.21 & -8.04 \\
\hline B3LYP/6-31++G(2d,2p) & -9.11 & -68.13 & -193.03 & -96.80 & -6.39 \\
\hline MP2/6-31+G(d,p) & -10.55 & -69.17 & -193.18 & -96.76 & -8.37 \\
\hline MP2/6-31++G(2d,2p) & -9.84 & -68.59 & -193.27 & -96.88 & -6.58 \\
\hline Experimental value & & & & -105 & -6.4 \\
\hline
\end{tabular}




\section{Figure captions}

Fig. 1 Histamine uptake into neonatal rat astrocytes at $37{ }^{\circ} \mathrm{C}$ and $4{ }^{\circ} \mathrm{C}$. Data for histamine uptake in the absence of $\mathrm{Na}^{+}$(full bar) and in the presence of ouabain (dotted bar) are also presented. $\mathrm{N}=6$, results were considered as statistically significant $\left(^{*}\right)$ for $\mathrm{P}<0.05$, df $=5$ as determined by independent samples t-test. ** designates $\mathrm{P}<0.0003$. Data represent mean $+/-$ SEM

Fig. 2 Concentration dependent $\left[{ }^{3} \mathrm{H}\right]$-histamine uptake (main) and specific histamine uptake rate (insert) into cultured rat neonatal astrocytes. Cultured astrocytes were incubated for $20 \mathrm{~min}$ at concentrations $0.125-100 \mu \mathrm{M}$ at $37{ }^{\circ} \mathrm{C}$ and $4{ }^{\circ} \mathrm{C}$. Specific uptake of $\left[{ }^{3} \mathrm{H}\right]$-histamine was calculated as the difference between the total $\left(\left[{ }^{3} \mathrm{H}\right]\right.$ histamine uptake at $37^{\circ} \mathrm{C}$ ) and non-specific (uptake of $\left[{ }^{3} \mathrm{H}\right]$-histamine at $4^{\circ} \mathrm{C}$ ). Kinetic parameter analysis of specific $\left[{ }^{3} \mathrm{H}\right]$-histamine uptake revealed $\mathrm{Km}$ of $5.2 \pm$ $2.1 \mu \mathrm{M}$ of and $\mathrm{Vmax}$ of $11.2 \pm 1.0 \mathrm{pmol} \mathrm{\textrm {mg } ^ { - 1 }}$ protein/min as determined by the best fit to $\mathrm{V}=\mathrm{Vmax} \cdot \mathrm{X} /(\mathrm{Km}+\mathrm{X})$, where $\mathrm{V}$ is the rate of uptake, $\mathrm{Vmax}-$ maximal rate of uptake, $\mathrm{X}$ - concentration of $\left[{ }^{3} \mathrm{H}\right]$-histamine and $\mathrm{Km}-$ affinity constant. Each point represents the mean \pm SEM of six determinations

Fig. 3 Structures of various tautomers of histamine calculated on MP2/6-31++G(2d,2p) level. Full geometry optimization was performed for all the species (a) neutral $\alpha$ tautomer, (b) neutral $\pi$ tautomer, (c) single protonated form, (d) double protonated form 


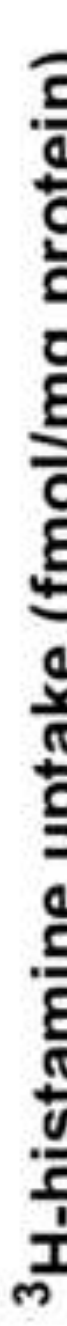

돓
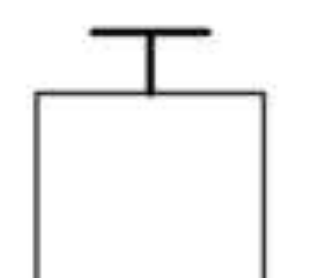

$\square$ control

$\square$ absence of $\mathrm{Na}^{+}$

$\ldots$ presence of ouabain

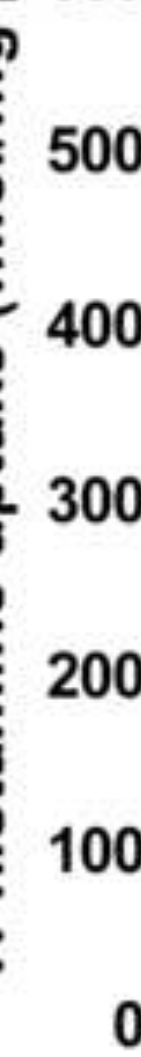

$500-$

$400-$

$100-$

0

*

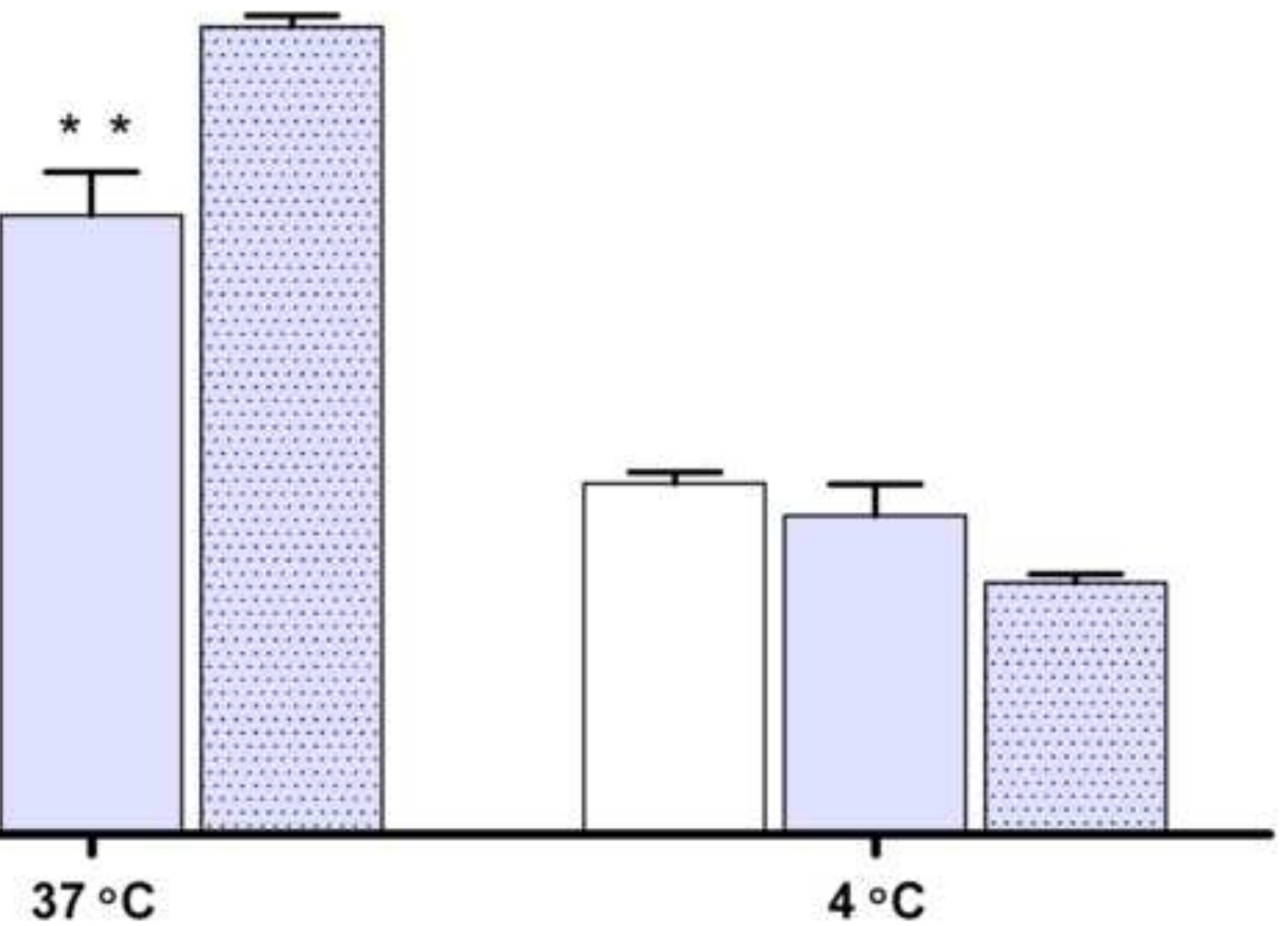




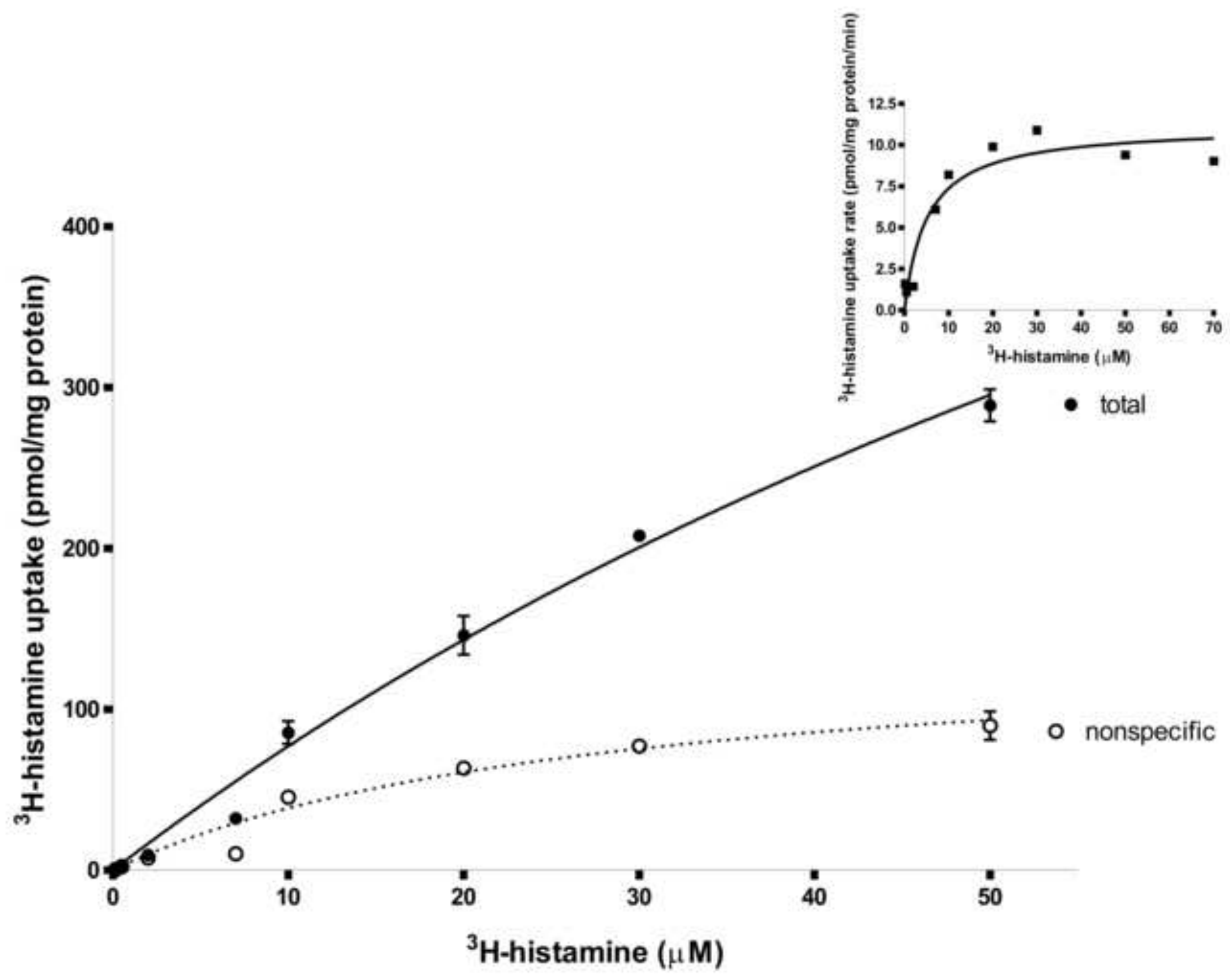



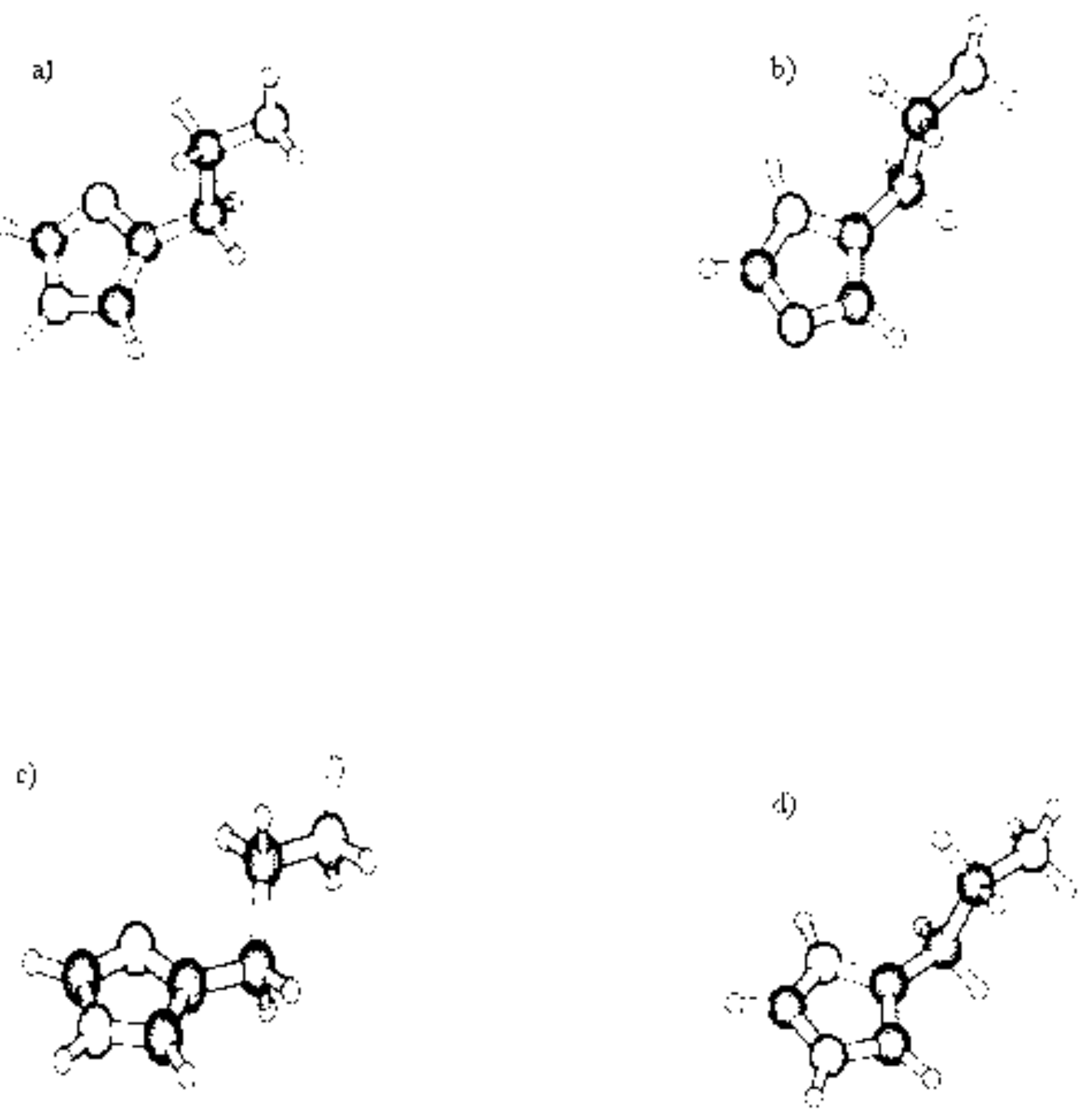